\title{
Prevalence and distribution of colonic diverticular disease from Ordu in Turkey
}

\author{
Nergis Ekmen ${ }^{1}$, Çağnı Akalın² \\ ${ }^{1}$ Gazi University, Faculty of Medicine, Department of Gastroenterology, Ankara, Turkey \\ ${ }^{2}$ Ordu Training and Research Hospital, Department of General Surgery, Ordu, Turkey
}

Received: 26 September 2019, Accepted: 20 November 2019, Published online: 31 December 2019

(C) Ordu University Institute of Health Sciences, Turkey, 2019

\begin{abstract}
Objective: Diverticulosis of the colon is the most frequent anatomical alteration diagnosed at colonoscopy. Most cases of diverticulosis in Western countries involve left side of the colon, while diverticulosis is predominantly present on the right side of the colon in Asian countries. With the aim of this study is to contribute to epidemiologic studies on colonic diverticula in Turkey located in Europe and Asian continent. We analyzed the data of patients undergoing colonoscopy with regard to age, gender, anatomic localization of diverticula retrospectively in the Ordu State Hospital in the Black Sea region.

Methods: We retrospectively reviewed a consecutive series of patients with regard to age, gender, location of diverticula and other colonoscopic lesions from an electronic endoscopic database who had undergone colonoscopy at the endoscopy unit of the Ordu State Hospital between 2016 and 2018. If diverticula were observed that distribution type was defined as cecum, ascending colon, transverse colon, descending colon, entire colon and sigmoid colon. In addition, we recorded that the additional diagnoses established in colonoscopic evaluations.

Results: We screened 2626 female (51.1\%) and 2511 male (48.9\%); totally 5137 patients from an electronic endoscopic database who had undergone colonoscopy. 227 (47.4\%) female, $252(52.6 \%)$ male, a total of 479 patients who had diverticulosis were included in this study. The mean age was determined female and male $65.44 \pm 12.01(\min 31-\max 91), 64.91 \pm 10.97(\min 27-\max 89)$ respectively and no statistically significant difference between two groups ( $\mathrm{p}>0.05)$. A total of 479 patients who had diverticulosis were divided into two groups: age $\leq 50(10.4 \%)$ and $50>429(89.6 \%)$. No significant difference was found with regard to diverticulosis localization between two groups ( $\mathrm{p}>0.05)$. The other colonoscopic diagnoses are as follows; hemorrhoid $(40.7 \%)$, polyp $(40.2 \%)$, inflammatory bowel disease $(4.7 \%)$ colorectal cancer $(0.9 \%)$, angiodysplasia $(2.3 \%)$, ulcer $(0.9 \%)$, anal fissure $(1.9 \%)$, parasitosis $(1.9 \%)$, terminal ileitis $(0.5 \%)$, nonspecific colitis $(3.7 \%)$, bowel surgery $(1.9 \%)$ and submucosal lesion $(0.5 \%)$.

Conclusion: Diverticular disease is a worldwide condition that affect elderly people with an increasing incidence in younger patients as well as in developing countries that have started adopting Western diets. So that in the future diverticular disease will induce a significant economic burden in terms of healthcare cost in Turkey. Despite its prevalence, its pathophysiology still remains poorly understood. There is a significant need for more studies to improve our understanding about diverticular disease.
\end{abstract}

Key words: Colonoscopy, colonic diverticular disease, diverticulosis localization.

Suggested Citation: Ekmen N, Akalin C. Surgically Prevalence and distribution of colonic diverticular disease from Ordu in Turkey. Middle Black Sea Journal of Health Science, 2019; 5(3): 206-211 


\section{Address for correspondence/reprints:}

\section{Çağrı Akalın}

Telephone number: +90 (452) 2250186

E-mail: dr.cagriakalin@gmail.com

DOI: $10.19127 / \mathrm{mbsjohs.622380}$

\section{Introduction}

The presence of the diverticula in the colon is known as diverticulosis. Diverticulosis is asymptomatic frequently in some patients. However, it can be symptomatic and complicated clinical course (Tursi et al., 2015).

For many years it has been assumed that most cases of diverticulosis were in the Western hemisphere and was due to the absence of fiber intake in the diet (Floch and Bina, 2004), nevertheless, recent studies show that the prevalence of diverticulosis has increased all over the World over the years (Alatise et al., 2012). The prevalence rates of diverticulosis were reported in Western and Asian countries 5-45\%, 13-25\%, respectively. In Western nations, diverticula primarily involve left-sided in contrast with Asian population, anatomic distribution is predominantly right-sided (Parks, 1969; Ngoi et al., 1992). Diverticulosis is often seen in a population of 70 years old (Painter and Burkitt, 1975). Diverticular disease clinically has been classified into four types; symptomatic complicated by diverticulitis, diverticular bleeding, segmental colitis and symptomatic uncomplicated diverticulitis (Imaeda and Hibi, 2018). Diverticular disease is the cause of a very high gastrointestinal symptom-related hospital admission. Its incidence has been shown to increase over time in both Western and Asian population (Nagata et al., 2014). This increase in the incidence of the disease will become a major of economic burden in terms of healthcare-costs (Imaeda and Hibi, 2018).

In this study, we intended to determine the prevalence and distribution of colonic diverticular disease from Ordu in Turkey.

\section{Methods}

Design of Study: This study was a retrospective and single-centre study. We analyzed the database of 5360 patients undergoing colonoscopy from December 2016 to January 2019 in Ordu State Hospital. Indication for colonoscopy were documented as follow; patients with lower GI complaints, asymptomatic patients with anemia; to screen patients with colorectal cancer in their family history, patients who required to screen for the positive faecal occult blood test, patients who underwent therapeutic endoscopy. We did not include patients with less than 18 years, those whose colonoscopic evaluation was restricted to the rectum, and patients with poorly stool cleaning. We excluded 223 patients who had one or more of the exclusion criteria. Finally, 5137 patients were selected for analysis and 449 patients had colonic diverticula. Diverticula was recorded in electronic endoscopy report according to anatomical localization. Distribution type was defined as the cecum, ascending colon, transverse colon, descending colon, entire colon and sigmoid colon. The information of patients were accessed from an electronic endoscopic database and archive files. The sample size was calculated with the incidence of diverticular disease (10\%) and population size (The population of Ordu centre is 750000) and was determined to be 4098 people in $95 \%$ confidence interval.

The patients were recommended clear liquid diet two days ago that were given sennoside $\mathrm{a}+\mathrm{b}$ calcium $500 \mathrm{mg} / 250 \mathrm{~mL}$ (X-M solution ${ }^{\circledR}$-Yenisehir Laboratory, Turkey) orally and sodium dihydrogen phosphate + disodium hydrogen phosphate (B.T. Enema ${ }^{\circledR} 210 \mathrm{~mL}-$ Yenisehir Laboratory, Turkey) rectally one day ago colonoscopy. The procedures were performed under general anesthesia with intravenous administration of $0,05 \mathrm{mg} / \mathrm{kg}$ midazolam (Midolam, Pharmada pharmacy, Turkey). Colonoscopic evaluation were performed with XQ Olympus (Olympus, Corporation, Tokyo, Japan) endoscopy device by gastroenterology specialist.

This study was approved by the institutional review Clinical Research Ethics Committee of Ordu University.

\section{Statistical analysis:}

All statistical analyses were performed with Statistical Package for Social Science (SPSS) software (IBM SPSS version 24.0 for Windows, Chicago, USA). $\mathrm{P}$ value less than 0.05 was considered as statistically significant. Descriptive statistics for continuous variables; mean, standard deviation (SD), minimum and maximum values; expressed as number and percentage for categorical variables. The Mann-Whitney U test was performed for continuous variables. The Pearson's chi-square test was used to determine the correlation between the categorical variables. 


\section{Prevalence and Distribution of Colonic Diverticular Disease}

\section{Results}

We screened 2626 female $(51.1 \%)$ and 2511 male (48.9\%); totally 5137 patients from electronic endoscopic reports. Among 227 (47.4\%) female, $252(52.6 \%)$ male, a total of 479 patients who had diverticulosis were included in this study. In terms of gender, detection rate of diverticulosis on colonoscopy that was found female and male; $8.6 \%$ (n: 227/2699), 10\% (n: 252/2511), respectively.

The mean age was determined female and male respectively $65.44 \pm 12.01 \quad(\min 31-\max 91)$, $64.91 \pm 10.97$ ( $\min 27-\max 89$ ) was no statistically significant difference between in two groups ( $>>0.05)$. Table 1 shows the distribution of diverticula on localization.
There was no statistically significant difference between age and localization. ( $>00.05)$. The incidence of diverticular disease in all patients evaluated under 50 years and older. A total of 479 patients who had diverticulosis were divided into two groups: age $\leq 50(10.4 \%)$ and age $>429(89.6 \%)$. No significant difference was found with regard to diverticulosis localization between two groups ( $p>0.05)$. Distribution of diverticula on gender and age groups are given in table 2 .

Other colonoscopic diagnoses were determined in $214(44,7 \%)$ patients. These diagnoses were shown in table 3 .

Table 1. The Distribution of Diverticula by Localization

\begin{tabular}{lcc}
\hline Localization & $\mathbf{N}$ & $\mathbf{\%}$ \\
\hline Cecum & 67 & 14 \\
\hline Ascending colon & 118 & 24,6 \\
\hline Transverse colon & 125 & 26,1 \\
\hline Descending colon & 324 & 67,6 \\
\hline Sigmoid colon & 379 & 79,1 \\
\hline Entire colon & 46 & 9,6 \\
\hline Total & 1059 & \\
\hline
\end{tabular}

N: Number, \%: Percent.

Table 2. Distribution of Diverticula on Gender and Age Group

\begin{tabular}{|c|c|c|c|c|c|c|}
\hline \multirow[b]{2}{*}{ Localization } & \multicolumn{2}{|c|}{ Gender } & \multirow{2}{*}{$\begin{array}{c}P \\
\text { value }^{*}\end{array}$} & \multicolumn{2}{|c|}{ Age } & \multirow{2}{*}{$\begin{array}{c}P \\
\text { value }^{*}\end{array}$} \\
\hline & $\begin{array}{l}\text { Female } \\
(\mathrm{n}=227)\end{array}$ & $\begin{array}{c}\text { Male } \\
(n=252)\end{array}$ & & $\begin{array}{c}\leq 50 \text { Age, } \% \\
(\mathrm{n}=50)\end{array}$ & $\begin{array}{c}>50 \text { Age, } \% \\
(\mathrm{n}=429)\end{array}$ & \\
\hline Cecum & $33(49,3 \%)$ & $34(50,7 \%)$ & 0,74 & $10(14,9 \%)$ & $57(85,1 \%)$ & 0,20 \\
\hline Ascending colon & $57(48,3 \%)$ & $61(51,7 \%)$ & 0,82 & $11(9,3 \%)$ & $107(90,7 \%)$ & 0,65 \\
\hline Transverse colon & $59(47,2 \%)$ & $66(52,8 \%)$ & 0,96 & $10(8 \%)$ & $115(92 \%)$ & 0,30 \\
\hline Descending colon & $153(47,2 \%)$ & $171(52,8 \%)$ & 0,92 & $23(7,1 \%)$ & $301(92,9 \%)$ & 0,01 \\
\hline Sigmoid colon & $172(45,4 \%)$ & $207(54,6 \%)$ & 0,87 & $31(8,2 \%)$ & $348(91,8 \%)$ & 0,02 \\
\hline Entire colon & $21(45,7 \%)$ & $25(54,3 \%)$ & 0,80 & $4(8,7 \%)$ & $42(91,3 \%)$ & 0,68 \\
\hline
\end{tabular}

*: Chi-square test was used. P value of $<0.05$ was considered statistically significant 
Table 3. Distribution of the Additional Diagnoses Established in Colonoscopic Examinations.

\begin{tabular}{lll}
\hline Diagnosis & $\mathrm{N}$ & $\%$ \\
\hline Hemorrhoids & 87 & 40,7 \\
\hline Polyp & 86 & 40,2 \\
\hline Inflammatory bowel disease & 10 & 4,7 \\
\hline Colorectal cancer & 2 & 0,9 \\
\hline Angiodysplasia & 5 & 2,3 \\
\hline Ulcer & 2 & 0,9 \\
\hline Anal fissure & 4 & 1,9 \\
\hline Parasitosis & 4 & 1,9 \\
\hline Terminal ileitis & 1 & 0,5 \\
\hline Nonspecific colitis & 8 & 3,7 \\
\hline Bowel surgery & 4 & 1,9 \\
\hline Submucosal lesion & 1 & 0,5 \\
\hline Total & 214 & \\
\hline
\end{tabular}

N: Number, \%: Percent.

\section{Discussion}

Diverticulosis of the colon is an anatomical change manifested by pouches in the wall of the colon. Diverticula occurs due to herniated mucosa and submucosa through the defect in the muscular layer of the colon. Impairment colonic motility is the most important preparatory factor in the development of diverticula. The pathophysiology of diverticula includes age, genetic factors, changing colonic motility, lifestyle conditions such as smoking, obesity, alcohol consumption, physical inactivity, fiber and meat intake with diet (Alessandra et al., 2018).

Recent research has indicated a rising in the prevalence of the diverticular disease in the world (Alatise et al., 2012). According to some studies conducted at the beginning of the 20th century; a diverticular disease incidence between $2-10 \%$ and $5-20 \%$ in patients in developing countries (Painter and Burkitt, 1971). Distribution of diverticular disease by gender tends to change over the years. Previously the diverticular disease was the most common in males. In addition, new studies represent that males under 50 years old have a higher incidence of disease. A study conducted in the United Kingdom showed that the disease is more often in females after the 4th decade (Warner et al., 2007). In some countries prevalence of the disease can be listed as follows: In Western countries 545\%, in Asia 13-25\%, in Lebanon 33\%, in the Far East $13-25 \%$, Korea $12 \%$ and Taiwan 14\% (Painter and Burkitt, 1971, Song et al., 2010; Sharara et al., 2013; Wang et al., 2015).
The diverticular disease is rare in sub-Saharan countries (Baako, 2001). Nigeria declared an incidence as low as $9.4 \%$ among patients that undergoing colonoscopic examination (Alatise et al., 2012). The incidence of diverticular disease is low in African countries too. Because African people have limited access to health care (Blachut et al., 2004).

Celebi et al. (2017) divided all patients into two groups as the age of 15-64 years and age of $\geq 65$ years. The incidence of diverticula was higher in the group over 65 year of age than age of 15-64 years ( $12.7 \%$ vs. $4.5 \%)$. However, no statistical difference was found between female and male patients at single center study in Turkey. Additionally, in this study, the frequency of diverticular disease was higher in the patients $50 \geq$ years old than in those under the age of $\leq 50$ years old. We also found no difference in the incidence of diverticular disease between female and male patients.

Celebi et al. (2017) presented that \%6.8 rate of diverticulosis in patients undergoing colonoscopy. Tamer et al. (2005) reported that diagnoses and rates as follows; hemorrhoid, polyps, ulcerative colitis, diverticula and colorectal cancer; $33.4 \%, 14.1 \%$, $4.7 \%, 4.1 \%$ and $3.7 \%$, respectively (12). Yilmaz et al. (2006) analyzed retrospectively the data of 322 patients who underwent colonoscopy. They explained that the disease rates as follows: hemorrhoid (17.7\%), polyps (14.9\%), ulcer $(12.4 \%)$ and masses (12.4\%) and did not report rate of diverticular disease. In our study, $40.7 \%$ hemorrhoid and diverticulosis $9.3 \%$ were detected 
and these rates are higher than Tamer et al. (2005) and Celebi et al. (2017). The total number of patients in the four different studies as follows; 2069 (Tamer et al., 2005), 322 (Yilmaz et al., 2006), 2831 (Celebi et al., 2017), and 5137 (our study).

Anatomical localization of the diverticula varies by race and geography. Diverticula are located only sigmoid colon in $65 \%$ of patients, in $24 \%$ of patients mainly located in the sigmoid colon, and in $\% 7$ of patients' diverticula involve entire colon in the Western and industrialized population (Parks, 1969). The Asian population, diverticula principally involves the right colon with a rate of approximately $\% 13$ to \%25 (Ngoi et al., 1992). In our population, distribution of diverticula; cecum $14 \%$, ascending colon $24.6 \%$, transverse colon $21.65 \%$, descending colon $67.6 \%$, sigmoid $79.1 \%$, entire colon $9.6 \%$ that reflected both Western and Asian population.

With the increasing incidence of diverticular disease continues to be a burden in terms of health care costs in Western and Asian countries (Imaeda and Hibi, 2018). According to our predict that the incidence of diverticular disease will increase because of rising elderly population over the years in Turkey. At the same time, the transition of a Western type lifestyle lead to an increase in diverticulosis incidence in youth patients. There are two important complications in diverticular disease: diverticulitis and diverticular bleeding. Diverticular bleeding occurs 5 to 15 percent among all patients. In 4 to 15 percent of patients with diverticular disease may develop diverticulitis (Imbembo and Bailey, 1992).

About 200000 patients have been admitted to the hospital each year due to symptoms related to diverticular disease in the United States (Peery et al., 2015). Delvaux (2003) reported that there were almost 800000 hospital admissions for diverticular disease in European countries. So that in the future diverticular disease will be a significant healthcare problem in Turkey. We need to know the true prevalence to reduce mortality and morbidity associated with diverticular disease. The number of large-scale studies should be increasing all over the world. Prevalence of diverticulosis has been estimated prospectively in several colonoscopybased studies in Asia. We can show the biggest deficiencies in our study as follows: unrecorded patient symptoms in the evaluation and the absence of out-hospital follow-up of the patients and this study was retrospective. We think that there is a need for multicentric epidemiological studies on this subject in Turkey.

\section{Conclusion}

Diverticular disease affects especially the elderly population in worldwide. However, new studies have begun to show an increased incidence in the young population. The most important reason for this is the developing countries that have started transition Western diets. Despite the rapid increase in the prevalence of the disease, its pathophysiology remains unresolved. Diverticular disease should be considered as a major burden of health-care cost for all over the world. There is a need for new studies to reduce the prevalence of diverticular disease.

Ethics Committee Approval: Ethics committee approval was received for this study from Clinical Research Ethics Committee of Ordu University.

Peer-review: Externally peer-reviewed.

Author Contributions Concept- N. E., Ç. A., Design- N.E., Ç. A., Supervision- N. E., Ç. A., Literature Review- N. E., Writing- N. E., Ç. A., Critical Review- N. E., Ç. A.

Conflict of Interest: No conflict of interest was declared by the author.

Financial Disclosure: The authors declared that this study hasn't received no financial support.

\section{References}

Alatise OI, Arigbabu AO, Agbakwuru EA, Lawal OO, Ndububa DA, Ojo OS. Spectrum of colonoscopy findings in Ile-Ife Nigeria. Niger Postgrad Med J 2012;19:219-24.

Alessandra V, Ginevra C, Chiara M, Alberto B, Antonio N, Mario C, et al. Epidemiology and risk factors for diverticular disease. Acta Biomed 2018;89:107-112.

Baako BN. Diverticular disease of the colon in Accra, Ghana. Brit J Surg 2001;88:1595.

Blachut K, Paradowski L, Garcarek J. Prevalence and distribution of the colonic diverticulosis. Review of 417 cases from Lower Silesia in Poland. Rom J Gastroenterol 2004;13:281-285.

Celebi A, Teker F, Gurler M, Koc DO, Ozdemir AA. Characteristics of the Patients Undergoing Colonoscopy in a Single Center within an 8-year Period. J Gastrointest Dig Syst 2017;7:3.

Delvaux M. Diverticular disease of the colon in Europe: epidemiology, impact on citizen health and prevention. Aliment Pharmacol Ther 2003;18:71-4.

Floch MH, Bina I. The natural history of diverticulitis: fact and theory. J Clin Gastroenterol 2004;38:2-7. 
Imaeda H, Hibi T. The burden of diverticular disease and its complications: west versus east. Inflamm Intest Dis 2018;3:61-68.

Imbembo AL, Bailey RW. Diverticular disease of the colon. In: Textbook of Surgery, 14th ed, Sabiston DC Jr (Ed), Churchill Livingstone, 1992. p.910.

Nagata N, Niikura R, Aoki T, Shimbo T, Itoh T, Goda $\mathrm{Y}$, et al. Increase in colonic diverticulosis and diverticular hemorrhage in an aging society: lessons from a 9-year colonoscopic study of 28,192 patients in Japan. Int J Colorectal Dis 2014;29:379-385.

Ngoi SS, Chia J, Goh MY, Sim E, Rauff A. Surgical management of right colon diverticulitis. Dis Colon Rectum. 1992;35:799-802.

Painter NS, Burkitt DP. Diverticular disease of the colon: a deficiency disease of Western civilization. Br Med J 1971;2:450-454.

Parks TG. Natural history of diverticular disease of the colon: a review of 521 cases. Br Med J. 1969;4:639-42.

Peery AF, Crockett SD, Barritt AS, Dellon ES, Eluri S, Gangarosa LM, et al. Burden of gastrointestinal, liver, and pancreatic diseases in the United States. Gastroenterology 2015;149:1731-1741.

Tamer A, Korkut E, Korkmaz U, Akcan Y. Low gastrointestinal endoscopy, an instutional results: Region of Duzce. The Medical Journal of Kocatepe 2005;6:29-31.

Sharara AI, El-Halabi MM, Mansour NM, Malli A, Ghaith OA, Hashash JG, et al. Alcohol consumption is a risk factor for colonic diverticulosis. J Clin Gastroenterol. 2013;47:420-5.

Song JH, Kim YS, Lee JH, Ok KS, Ryu SH, Lee JH, et al. Clinical characteristics of colonic diverticulosis in Korea: a prospective study. Korean J Intern Med 2010;25:140-6.

Tursi A, Inchingolo CD, Picchio M, Elisei W, Mangiola F, Gasbarrini G. Histopathology of segmental colitis associated with diverticulosis resembles inflammatory bowel diseases. J Clin Gastroenterol 2015;49:350-1.

Yilmaz S, Bayan K, Tuzun Y, Canoruc F. Colonoscopic lesions and histopathological results: evalutation of 322 patients. The Turkish Journal of Academic Gastroenterology 2006;5:184-187.

Wang FW, Chuang HY, Tu MS, King TM, Wang $\mathrm{JH}$, Hsu CW, et al. Prevalence and risk factors of asymptomatic colorectal diverticulosis in Taiwan. BMC Gastroenterol 2015;15:40.
Warner E, Crighton EJ, Moineddin R, Mamdani M, Upshur R. Fourteen-year study of hospital admissions for diverticular disease in Ontario. Can J Gastroenterol 2007;21:97-9.. 